\title{
Growth rules based on the modularity of the Ganarian Aeonium (Crassulaceae) and their phylogenetic value
}

\author{
TOVE H. JORGENSEN* AND JENS M. OLESEN \\ Department of Ecology and Genetics, University of Aarhus, Ny Munkegade Block 540, \\ DK-8000 Aarhus C, Denmark
}

Received November 1998; accepted for publication fuly 1999

Growth forms of 22 species of Aeonium (Crassulaceae) were quantified. Since all species are simple in their modular construction, models were developed to predict module length, branching mode and flowering probability using linear and logistic regression. When combined, the parameters of these models are species specific. A discriminant analysis generates a statistically significant separation of species at the level of phylogenetic sections. The results therefore demonstrate the phylogenetic value of growth rules in plants. This dynamic approach strongly contrasts with the traditional static view on forms in systematics and morphology. It also leaves scope for predicting the evolutionary pathways of morphological change which have caused the great diversity of growth forms in the genus Aeonium.

c 2000 The Linnean Society of London

ADDITIONAL KEY WORDS:-adaptive radiation - Canary Islands - dynamic morphology - modular growth - plant architecture.

Introduction . . . . . . . . . . . . . . . . . . . . . . . 224

Material and methods . . . . . . . . . . . . . . . . . . . . . . . 226

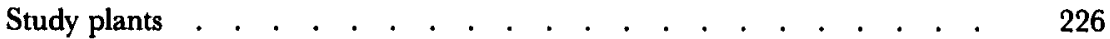

Description of growth forms . . . . . . . . . . . . . . . . 227

Sampling and measurements . . . . . . . . . . . . . . . . 228

Results

Statistics . . . . . . . . . . . . . . . . . . 231

Modelling of growth . . . . . . . . . . . . . . . . . . 232

The phylogenetic value of growth rules . . . . . . . . . . . . 236

Adaptive radiation and evolution . . . . . . . . . . . . . . 236

Discussion . . . . . . . . . . . . . . . . . . . . . . . 237

Modelling of growth . . . . . . . . . . . . . . . . . . 237

The phylogenetic value of growth rules . . . . . . . . . . . . 238

Adaptive radiation and evolution . . . . . . . . . . . . . . 238

Acknowledgements . . . . . . . . . . . . . . . . . . 239

References . . . . . . . . . . . . . . . . . . . . 240

* Corresponding author. E-mail: Tove.Joergensen@biology.au.dk 


\section{INTRODUCTION}

Plants grow by the repeated production of constructional units, thus conforming to the definition of modular organisms as those that grow by a reiteration of modules (Bell, 1991). The modularity of a plant is expressed at different hierarchical levels of morphological organization (Harper, 1977). Carex arenaria is modular in its growth and extension by stolons; Equisetum arvense is modular in its production of series of internodes with whorls of scale leaves; and trees can be regarded as built of modules each consisting of an internode, a node, a leaf and an axillary bud. Because of its modularity, a plant is a plastic structure, responsive to a variable environment. The number of modules it produces varies as well as the rate by which they are produced and the size and general morphology of the module itself. The question is how much of the overall growth form is unpredictable and how much can be attributed to general growth rules with a genetic background.

Viewing plants as modular, plastic organisms has been the starting point for a dynamic approach to plant morphology. Traditional static morphology on the other hand, developed as it was mainly by taxonomists, focused on the classification and ontogeny of the various plant structures or organs. Hallé, Oldeman \& Tomlinson (1978) made a major contribution to dynamic morphology in their work on tropical trees. Their generalizations on growth and branching enabled a classification into a total of 24 models of tree development. The variables in these descriptive models included branch construction, rhythmicity of growth, determination in growth and flowering and stochastic events in terms of variation in reiteration and metamorphosis. In their application of the term, a module is a shoot with determinate growth. The same concept of morphological classification has been applied to herbs and lianas (for review see Bell, 1991). In this context, the plasticity of plant growth is in the variation in the repetition of modules and in the reiteration of growth models from new meristems when plants are damaged or dormancy is broken. Bell (e.g. 1974, 1984) and Bell \& Tomlinson (1980) have made other theoretical and empirical contributions to the dynamic plant morphology approach with their work on, among other things, rhizomatous plants. The modular approach to plant morphology has not only renewed the discipline per se but has also created new concepts in other fields of plant biology, for example in demography (Harper, 1977) and foraging behaviour (Sutherland \& Stillmann, 1988; Hutchings \& de Kroon, 1994). In a demographic analysis, an individual plant is regarded as a population of modules (a 'metapopulation' sensu White, 1979).

Resource acquisition, reproduction and competitive ability are expected to contribute to optimal fitness of the plant (Fisher, 1986). When focusing on overall growth form and not on single organs, these life-history parameters are thought to be optimized through selection operating on the morphology of the modules and on the dynamics of the iteration process. One approach to the study of evolution of growth form in modular organisms would therefore be to separate the selection regime into those forces affecting the appearance of the module and those working on the iterative production of modules. However, selection will operate only within the constraining limits of the phylogeny, and the ultimate unit of evolution is the genet.

Even small deviations in the morphology of the individual module will be magnified by the iteration process and result in very different final growth forms. A high diversity of forms within a group of species could therefore give a false impression 


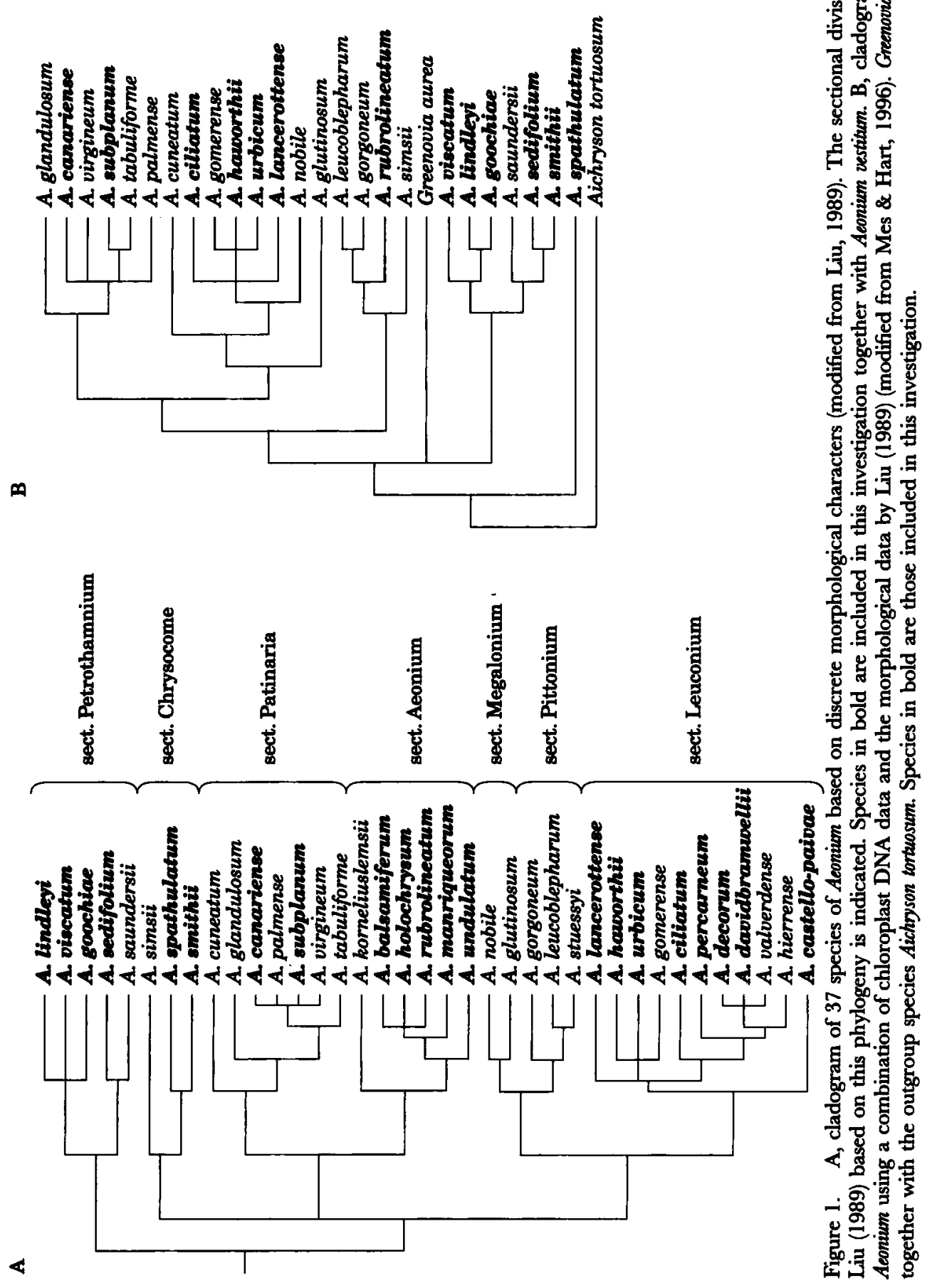


that the species have evolved far from each other. This issue of simplicity in the evolution of growth forms in modular plants has not yet been addressed. So far, no detailed quantifications of modular growth patterns have been conducted within a species group for comparative purposes. The aim of this study is to demonstrate the presence of an underlying simplicity in plant form evolution by reducing a high form diversity in a species group to a few simple rules for module growth. Our truly mechanistic approach to this issue may, together with adaptational and phylogenetic explanations, contribute to a more complete understanding of form diversity in nature.

In order to demonstrate this, a highly morphologically diverse species group is needed, preferably with a supposed simple modular construction. The Canarian succulent genus Aeonium (Crassulaceae) meets these requirements. Our quantification of growth forms is interpreted evolutionarily in view of existing phylogenies of the genus. These are based on morphological (Liu, 1989) and molecular data (Mes \& Hart, 1996) (Fig. 1). We describe module variation and the iteration process of a set of Aeonium species and make comparisons among them. Three questions are addressed:

(1) Modelling of growth. Can simple models describe the growth of modular species?

(2) The phylogenetic value of growth rules. Is there any consistency between traditional phylogenies and clustering of growth rule models?

(3) Adaptive radiation and evolution. How does the clustering of model parameters fit the general predictions on the evolution and radiation of Aeonium on the Canary Islands?

The first question is answered by relating the variation in module morphology to the position of the modules on the plant. This is done using regression models with the independent variables indicating the position of the module. Module morphology. is described by its length, its probability of branching and its probability of turning into a flower. For each morphological variable, regression models, or growth rule models, for each Aeonium species are constructed and the parameters of these models are compared to answer the second question. If closely related species of Aeonium have similar parameters of the growth rule models, growth form as described by the regression models has a phylogenetic component. A similar comparison of the parameters from species occurring on the same island in the Canarian archipelago or in the same habitat provides an answer to our third question. If selection has favoured certain growth forms on certain islands or in certain habitats, these groups of species will have similar parameters of the growth rule models.

\section{MATERIAL AND METHODS}

\section{Study plants}

Aeonium is a genus of 37-39 taxa (Liu, 1989; Bramwell \& Bramwell, 1990) largely confined to the Canary Islands (31-33 taxa), the remainder being distributed in Madeira (2) and the Cape Verde Islands (1), Yemen and East Africa (2) and Morocco (1). All taxa will be referred to as species, as in Bramwell \& Bramwell (1990). The species are divided into seven sections according to Liu (1989) (Fig. 1A). Most of 
the Canarian species are single-island endemics, local in occurrence and limited to certain habitat types. They are thus separated fairly distinctly along gradients of both habitat type and islands (Bramwell \& Bramwell, 1990; Voggenreiter, 1974).

Until recently the genus was believed to be of Tertiary origin having immigrated to Macaronesia from northern Africa. The ancestor was hypothesized to have had a woody growth form resembling that of the extant species in Africa (Lems, 1960; Liu, 1989). According to this view the present disjunct distribution arose after the formation of the Sahara Desert (Sunding, 1979; Liu, 1989). Recent molecular investigations of the genus have cast doubt on this hypothesis (Mes, van Brederode \& Hart, 1996). These data indicate that the genus evolved in situ on the Canary Islands from a herbaceous ancestor, migrating to Africa and other Macaronesian archipelagos at a later stage while evolving a woody habit.

Lems (1960) classified the species qualitatively according to their growth form and related this diversity to the various Canarian habitats: well-anchored species with adventitious roots occur at windy sites, species with compact vegetative bodies are restricted to the subalpine zone; unbranched species grow in small soil pockets. Apart from the descriptive study of Lems, and the morphological and molecular studies on the genus by Liu (1989) and Mes \& Hart (1996) respectively, other discussions about its origin and its pattern of radiation have been based on geographical and morphological (Praeger, 1928; Liu, 1989) and biochemical data (Pilon-Smits et al., 1992; Stevens, Hart \& Wollenweber, 1995).

\section{Description of growth forms}

Subjected to the changing seasons of the Canary Islands, the succulent rosulate species of Aeonium have a rhythmic growth pattern with a dormant period during the dry summer (June-September), when there is either little or no growth and elongation of the stem, thus resulting in a decrease in interleaf distances. Growth occurs in the wet season, causing continuous formation of leaves accompanied by stem extension. It is thus possible actually to map the life history of each individual plant by identifying areas of dense 'summer leaf scars' and more scattered 'winter scars' (pers. observ.).

The branching system of Aeonium plants is a hierarchy of shoots of increasing order. A branch is defined as one to a few interconnected shoots. Each shoot consists of a few to several modules, a module representing one year's growth along a shoot, i.e. the distance from one dense summer rosette to the next (Fig. 2). In our application of the term, a module is therefore the piece of stem with its leaves and branches formed during one year of growth. After a number of repetitions of the module, the shoot eventually terminates in an inflorescence.

A major subdivision of the genus, based on overall growth form and independent of taxonomic subdivisions, is into creeping species and upright, tall ones (Table 1, Fig. 3). Creeping species have a few rosettes near the ground and spread by stolons. Upright species are here further grouped into shrubs and subshrubs. Subshrubs are rarely taller than $50 \mathrm{~cm}$, are much-branched and have extensive periderm formation on older branches. Shrubs are usually taller than $1 \mathrm{~m}$, have fewer branches and no periderm formation on older branches. The latter variable is the important distinctive factor between the two growth forms in this study. The unbranched $A$. urbicum is similar to the shrubs in having no periderm formation on older branches. 


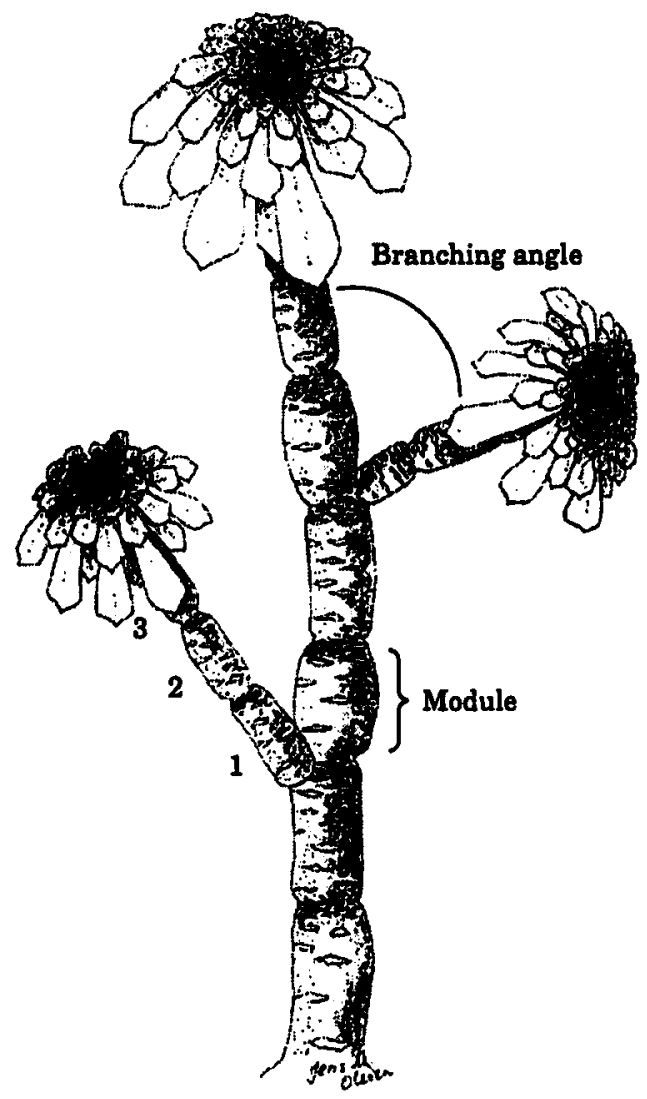

Figure 2. A branch of Aeonium with a module and branching angle indicated. Numbering of modules starts at one at the base of each shoot.

\section{Sampling and measurements}

Individuals representing 22 species of Aeonium were studied during January, March and May 1997 and March and April 1998 on Tenerife, Gomera, Gran Canaria, Lanzarote and La Palma. Samples of each species were from single localities except for $A$. ciliatum, $A$. sedifolium and $A$. smithii which were sampled from several small adjacent populations in order to obtain a sample size sufficiently large for statistical analyses (Table 1). Within populations, individual plants were sampled at random. Length of the modules of each plant was measured and the number of shoots originating from each module was recorded, as was presence of any inflorescences. Branching angle was measured as the angle between the mother shoot and the first module of a daughter shoot. Shrubs were mapped in full and all their modules were aged. The total number of rosettes formed in any given year (the sum of all modules within a generation) counted as a measure of plant size. The relationship between the number of rosettes and the age, i.e. module generation, of the plant was linear in the size range of the plants in this investigation (data not shown). Modules of each shoot were numbered in sequence from the base to the shoot tip (Fig. 2). This number of a module, which refers to its position on a shoot, is hereafter termed 'module position'. 
GROWTH RULES AND PHYLOGENY IN AEONIUM

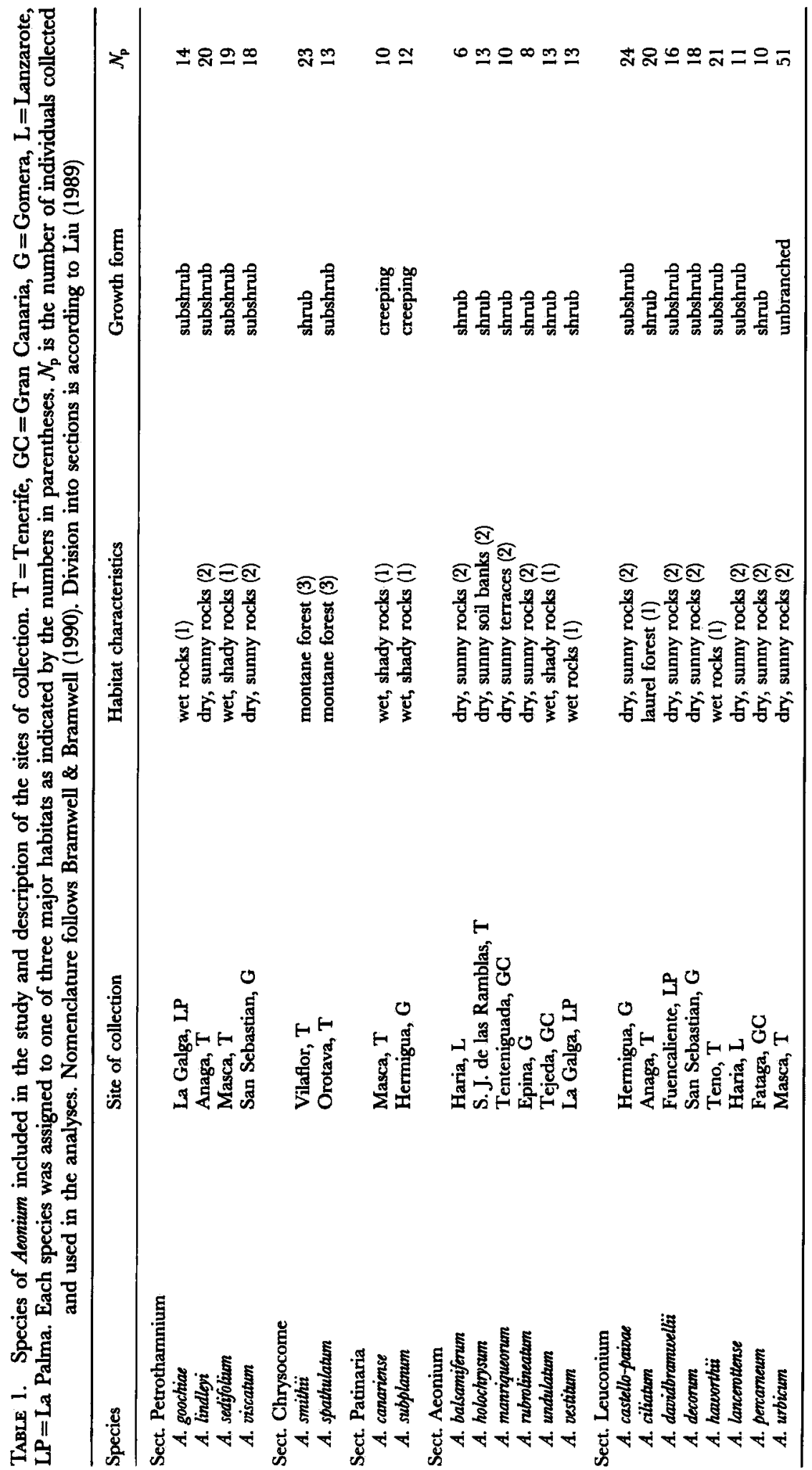



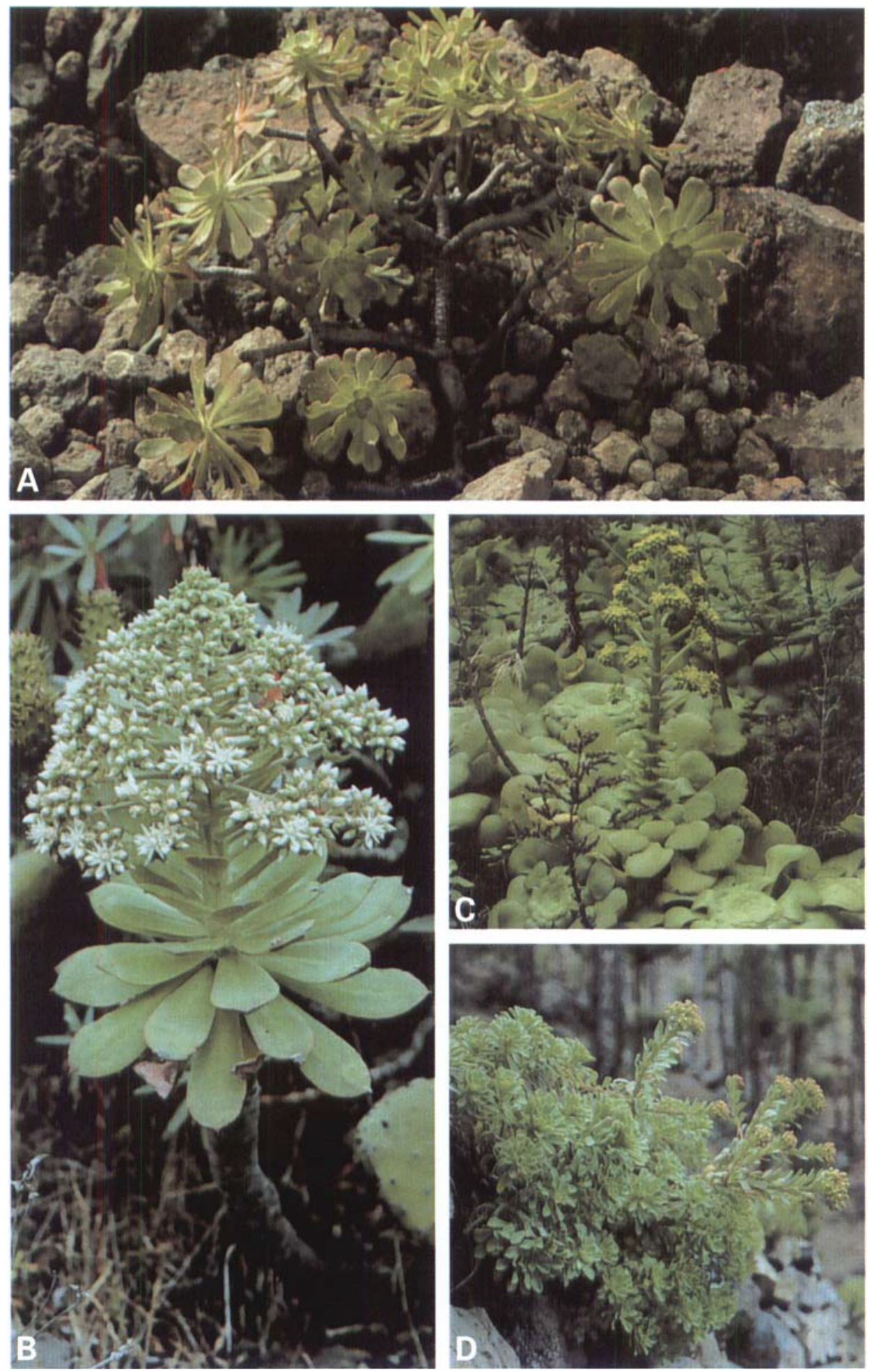

Figure 3. Growth forms in Aeonium: A, shrub (A. rubrolineatum). B, unbranched form (A. urbicum). C, creeping form (A. subplanum). D, subshrub (A. spathulatum). 
In subshrubs, generations of modules could only be traced five to ten years back in time because intense periderm formation on older branches had blurred any leaf scars. Therefore, only one randomly sampled branch per plant was mapped. The total number of rosettes formed per plant in each post year was estimated by extrapolating from the decrease in rosettes on the branch analysed to the whole plant. Total number of rosettes on the plant in the year of sampling was used as the starting point for extrapolation.

In general, individual modules on creeping plants could not be discerned from the pattern of leaf scars. Because of small increments of growth between successive summers and densely aggregated, often persistent leaves on the stems, mapping was associated with considerable error. Instead, an investigation of the secondary xylem in a longitudinal cut of the stem revealed the amount of growth in separate years and helped identify the modules. Phloroglucinol-HCL was used as a dye for xylem (Jensen, 1962).

\section{Harvesting and conservation considerations}

All measurements of shrubs and subshrubs were made in situ on otherwise undisturbed plants. The two species with a creeping habit, $A$. canariense and $A$. subplanum, were harvested for further measurements in the laboratory. This was done with the permission of Consejeria de Politica Territorial, Viceconsejeria de Medio Ambiente in the Canary Islands.

\section{Statistics}

\section{Modelling of growth}

The variables describing the morphology of the module-i.e. length, number of branches and presence of any inflorescence - were turned into rules of growth by performing multiple regression analyses with each of these as dependent variables. In addition, branching angles were modelled. In these models, module position on the shoot and plant size (number of rosettes) were independent variables. In models of branching angles, plant size was the only independent variable. The sign of the parameters in such models indicates any increase or decrease of the variable being modelled when the shoot gets older (i.e. the module position increases) or the plant increases in size (i.e. the rosette number increases). The numerical value of the parameters indicates the extent of this increase or decrease. Differences between species in these parameters will reflect differences in growth rules, i.e. in growth forms.

The variation in the length of the module was modelled for each species using linear multiple regression analyses with module position and rosette number (plant size) as independent variables. A stepwise elimination modelling procedure was used (Sokal \& Rohlf, 1995). In order to obtain normality, module lengths were logtransformed. Co-linearity between the two independent variables can be ruled out: from the way they are defined, correlation between module position and plant size is illogical. Numbering of module position starts at one on every single shoot, at the base of small plants as well as at higher levels of large and old plants.

Due to the nominal nature of the data on branching, logistic regressions were performed to model branching. With module position and rosette number as 
independent variables, the probability of branching along a shoot (module position) and with increasing plant size (rosette number) was investigated for each species. Stepwise elimination modelling procedure was used (Sokal \& Rohlf, 1995). To assess how well the logistic models fit data, predictions were compared with observed outcomes for each model (Hosmer \& Lemeshow, 1989). As branching is a much rarer event than not branching, the two events were not assigned equal probabilities. Instead, the frequencies of the two events in the whole data set of a species were used as prior probabilities. The correctly predicted events were summed and expressed as a percentage of the total number of observations (Hosmer \& Lemeshow, 1989).

As with branching, the data on flowering were of a nominal nature. Logistic regressions with module position and rosette number as independent variables were therefore performed to investigate the variation in a species' probability of flowering along the shoot and with increasing plant size. Stepwise elimination modelling procedure was used (Sokal \& Rohlf, 1995). Models were evaluated as the percentage of correctly predicted events, as explained above for branching probabilities.

The limited range of possible values of the branching angles $\left(0^{\circ}-180^{\circ}\right)$ justifies the data being treated as continuous rather than circular (Zar, 1984). In the majority of species, angles conformed to a normal distribution. Simple regressions of branching angle on plant size were performed to investigate the variation.

\section{The phylogenetic value of growth rules}

To test whether the variation in growth rules of the 22 species of Aeonium conforms to the phylogeny of the genus, a discriminant analysis was applied using coefficients and constants of the regression models in the former analyses as predictor variables. Species were sorted according to the phylogenetic sections of Liu (1989) (Fig. 1A). A discriminant analysis separates groups of species (here, phylogenetic sections) by calculating uncorrelated linear combinations of the predictor variables so that any variation within groups is minimized relative to that among groups. The first function will explain the largest inter-group variation (Norusis, 1994). If similar growth rules apply to species of the same groups, these will be significantly separated in the analysis. Non-significant coefficients in the regression models were entered as zeros in the analysis.

\section{Adaptive radiation and evolution}

A discriminant analysis was applied with species sorted according to (1) islands, or (2) habitats (Table 1) and with the parameters of the growth rules models as predictor variables. If the same growth rules apply to species of the same island or same habitat, these species groups will be separated in the discriminant analyses.

\section{RESULTS}

\section{Modelling of growth}

All but four species had linear changes in module length with increasing module position and/or with increasing plant size (Table 2). In nine species, the length of the module increased apically along the shoot, i.e. there was a significant positive 
TABLE 2. Multiple regression models of module length on the independent variables module position and plant size. Coefficients of the independent variables are shown in the columns 'module' and 'size' and constants in the column 'constant'. Only significant values are shown $(P<0.05)$. $F$-values are from significance tests of the models $\left(P<0.05:^{*}, P<0.01:^{* *}, P<0.001:^{* * *}, P>0.05 \mathrm{~ns}\right)$. Degrees of freedom equal the number of significant independent variables, $k$, in the model. Error variation is based on $\mathcal{N}_{\mathrm{m}}-\mathrm{k}-1 \mathrm{df}$. $\mathcal{N}_{\mathrm{m}}$ is the total number of modules on which the models were based. Module lengths were transformed to their natural logarithms. The model of $A$. urbicum is a simple regression on module position as it never had more than one rosette

\begin{tabular}{|c|c|c|c|c|c|c|}
\hline Species & Constant & $\begin{array}{c}\text { Model } \\
\text { Module }\end{array}$ & Size & $\mathbf{R}_{\text {adj }}^{2}$ & $\mathcal{N}_{\mathrm{m}}$ & $F$ \\
\hline $\begin{array}{l}\text { Sect. Petrothamnium } \\
\text { A. goochiae } \\
\text { A. lindleyi } \\
\text { A. sedifolium } \\
\text { A. viscatum }\end{array}$ & $\begin{array}{l}3.86 \\
3.82 \\
2.71 \\
3.70\end{array}$ & $\begin{array}{l}-0.15 \\
-0.24 \\
-0.26\end{array}$ & $\begin{array}{r}0.004 \\
-0.001\end{array}$ & $\begin{array}{l}0.11 \\
0.20 \\
0.00 \\
0.17\end{array}$ & $\begin{array}{l}118 \\
194 \\
393 \\
184\end{array}$ & $\begin{array}{c}8.09^{* * *} \\
24.58^{* * *} \\
0.15 \mathrm{~ns} \\
37.65^{* * *}\end{array}$ \\
\hline $\begin{array}{l}\text { Sect. Chrysocome } \\
\text { A. smithii } \\
\text { A. spathulabum }\end{array}$ & $\begin{array}{l}3.68 \\
2.75\end{array}$ & -0.11 & $\begin{array}{c}-0.04 \\
0.003\end{array}$ & $\begin{array}{l}0.09 \\
0.10\end{array}$ & $\begin{array}{l}259 \\
153\end{array}$ & $\begin{array}{l}13.37^{* * *} \\
17.29^{* * * *}\end{array}$ \\
\hline $\begin{array}{l}\text { Sect. Patinaria } \\
\text { A. canariense } \\
\text { A. subplanum }\end{array}$ & $\begin{array}{l}2.81 \\
3.15\end{array}$ & 0.06 & & $\begin{array}{l}0.08 \\
0.00\end{array}$ & $\begin{array}{l}66 \\
35\end{array}$ & $\begin{array}{l}6.93^{*} \\
0.41 \mathrm{~ns}\end{array}$ \\
\hline $\begin{array}{l}\text { Sect. Aeonium } \\
\text { A. balsamifenum } \\
\text { A. holochysum } \\
\text { A. manriqueorum } \\
\text { A. nubrolineatum } \\
\text { A. undulatum } \\
\text { A. vestitum }\end{array}$ & $\begin{array}{l}4.32 \\
3.51 \\
3.52 \\
3.24 \\
3.73 \\
3.96\end{array}$ & $\begin{array}{r}-0.18 \\
0.17 \\
0.80 \\
0.10 \\
0.14\end{array}$ & $\begin{array}{l}-0.01 \\
-0.0002 \\
-0.02 \\
-0.008\end{array}$ & $\begin{array}{l}0.22 \\
0.28 \\
0.11 \\
0.34 \\
0.19 \\
0.00\end{array}$ & $\begin{array}{l}150 \\
952 \\
986 \\
914 \\
582 \\
113\end{array}$ & $\begin{array}{r}44.21^{* * *} \\
188.66^{* * *} \\
59.51^{* * *} \\
235.777^{* * *} \\
71.10^{* * *} \\
0.49 \mathrm{~ns}\end{array}$ \\
\hline $\begin{array}{l}\text { Sect. Leuconium } \\
\text { A. castello-paivace } \\
\text { A. ciliatum } \\
\text { A. davidbramwellii } \\
\text { A. decorum } \\
\text { A. haworthii } \\
\text { A. lancerottense } \\
\text { A. percameum } \\
\text { A. urbicum }\end{array}$ & $\begin{array}{l}3.38 \\
3.89 \\
3.85 \\
3.06 \\
3.30 \\
3.68 \\
3.64 \\
3.07\end{array}$ & $\begin{array}{r}0.11 \\
0.10 \\
\\
0.20 \\
-0.06 \\
-0.07 \\
-0.02 \\
0.21\end{array}$ & $\begin{array}{l}0.001 \\
0.01\end{array}$ & $\begin{array}{l}0.01 \\
0.07 \\
0.00 \\
0.04 \\
0.04 \\
0.03 \\
0.02 \\
0.19\end{array}$ & $\begin{array}{r}327 \\
250 \\
61 \\
141 \\
342 \\
95 \\
602 \\
168\end{array}$ & $\begin{array}{c}5.39^{*} \\
18.32^{* * *} \\
0.02 \mathrm{~ns} \\
7.15^{* *} \\
8.53^{* * *} \\
4.28^{*} \\
5.90^{* * *} \\
39.29^{* * *}\end{array}$ \\
\hline
\end{tabular}

effect of module position in the regression models. In five species the module length was constant along the shoot (no significant effect of module number) and in eight species the module decreased in length towards the shoot apex (negative effect of module position). In ten species, variation in plant size explained a significant part of the variation in module length. Six of these had decreasing module length with increasing plant size. Hence, in these species modules became progressively shorter the older the plant. When evaluated from the $\mathbf{R}^{2}{ }_{\text {adj }}$, regression models with the greatest amounts of variation in module length explained are those applied to shrubs. Modelling of subshrubs frequently gave low coefficients of determination.

Branching probability as a function of module position and plant size is shown in Table 3. When $\ln [\mathrm{B} /(1-\mathrm{B})]>0$ in the logistic equations, the probability of branching, $B$, exceeded that of not branching. Species in which the onset of branching in individual plants occurred late in life, e.g. A. rubrlineatum and $A$. percameum, had constants of high negative value and/or small coefficients of the independent variables module position and plant size. In three species- $A$. ciliatum and the two creeping species from the 
TABLE 3. Multiple logistic regression models of branching probability, $B$, on module position, $m$, and plant size, $r: \ln \left[B /(1-B)=c+a_{1}{ }^{*} m+a_{2}{ }^{*}\right.$. Coefficients $a_{1}$ and $a_{2}$ of the independent variables are shown in the columns 'module' and 'size', and constants, $c$, in the column 'constant'. Only significant values are shown $(P<0.05)$. $G$-statistics and significance of the entire model are given. Degrees of freedom equal the number of significant variables in each model. Abbreviations as in Table 2. The correspondence between model predictions and actual data is shown in the column 'correctly predicted'. Number of branches per branching module is given as mean \pm 1 SD with number in parentheses being the number of modules in the sample

\begin{tabular}{|c|c|c|c|c|c|c|c|}
\hline Species & Constant & $\begin{array}{c}\text { Model } \\
\text { Module }\end{array}$ & Size & $G$ & $\mathcal{N}_{\mathrm{m}}$ & $\begin{array}{l}\text { Correctly } \\
\text { predicted }\end{array}$ & No. branches \\
\hline \multicolumn{8}{|l|}{ Sect. Petrothamnium } \\
\hline A. goochiae & -3.67 & 1.75 & & $70.31^{* * *}$ & 205 & 0.82 & $1.48 \pm 0.69(64)$ \\
\hline A. lindlgyi & -2.99 & 1.20 & & $63.70^{* * *}$ & 289 & 0.76 & $1.36 \pm 0.62(90)$ \\
\hline A. sedifolium & -3.67 & 2.05 & & $168.48^{* * *}$ & 493 & 0.85 & $1.39 \pm 0.66(185)$ \\
\hline A. viscatum & -2.82 & 1.23 & & $42,83^{* * *}$ & 205 & 0.66 & $1.35 \pm 0.64(66)$ \\
\hline \multicolumn{8}{|l|}{ Sect. Chrysocome } \\
\hline A. smithii & -3.30 & 0.51 & & $14.42^{* * * *}$ & 259 & 0.78 & $1.35 \pm 0.63(26)$ \\
\hline A. spathulatum & -3.47 & 0.90 & & $23.38^{* * *}$ & 184 & 0.79 & $1.97 \pm 0.91(31)$ \\
\hline \multicolumn{8}{|l|}{ Sect. Patinaria } \\
\hline A. canariense & -2.67 & & & $0.18 \mathrm{~ns}$ & 74 & 0.96 & $1.33 \pm 0.52(8)$ \\
\hline A. subplanum & -3.98 & & & $0.86 \mathrm{~ns}$ & 38 & 0.71 & $1.00 \pm 0.00(2)$ \\
\hline \multicolumn{8}{|l|}{ Sect. Aeonium } \\
\hline A. balsamiferum & -1.64 & & -0.08 & $6.90^{*}$ & 302 & 0.72 & $2.90 \pm 1.75(30)$ \\
\hline A. holochyysum & -4.90 & 0.86 & & $166.08^{* * *}$ & 952 & 0.78 & $1.80 \pm 0.94(112)$ \\
\hline A. manriqueonum & -3.73 & 0.03 & & $91.36 * * *$ & 986 & 0.69 & $1.75 \pm 0.90(141)$ \\
\hline A. rubrolineatum & -5.30 & 0.59 & & $57.84^{* * *}$ & 913 & 0.68 & $1.49 \pm 0.69(45)$ \\
\hline A. undulatum & -1.41 & -0.37 & -0.08 & $18.10^{* * *}$ & 582 & 0.64 & $8.00 \pm 13.44(19)$ \\
\hline A. vestitum & -4.16 & 0.46 & & $86.10^{* * *}$ & 533 & 0.75 & $1.63 \pm 0.90(82)$ \\
\hline \multicolumn{8}{|l|}{ Sect. Leuconium } \\
\hline A. castello-paivae & -3.94 & 1.33 & & $48.81^{* * *}$ & 327 & 0.73 & $2.26 \pm 1.56(53)$ \\
\hline A. ciliatum & -1.96 & & & $0.34 \mathrm{~ns}$ & 324 & 0.12 & $2.35 \pm 1.82(40)$ \\
\hline A. davidbramwellii & -5.37 & 1.36 & & $34.05^{* * *}$ & 142 & 0.84 & $3.06 \pm 2.32(16)$ \\
\hline A. deconum & -4.57 & 2.17 & & $32.33^{* * * *}$ & 141 & 0.84 & $2.07 \pm 1.28(28)$ \\
\hline A. haworthii & -3.00 & 0.63 & & $33.06^{* * *}$ & 342 & 0.73 & $1.97 \pm 1.09(62)$ \\
\hline A. lancerottense & -3.21 & 0.42 & & $36.77^{* * *}$ & 460 & 0.75 & $1.84 \pm 1.24(76)$ \\
\hline A. percamerm & -3.56 & 0.24 & & $16.75^{* * *}$ & 603 & 0.63 & $2.09 \pm 1.43(47)$ \\
\hline A. urbicum & & & & & 167 & & \\
\hline
\end{tabular}

section Patinaria -neither of the two independent variables had any effect on branching probability, i.e. branching and not branching were equally likely at any module or any plant size. In all other species branching probability varied with either module position or plant size or, in the case of $A$. undulatum, with both. This latter species was the only one to show decrease in branching probability with increasing module position, reflecting its tendency to branch at the base of the main stem. It only branched at higher module positions if the meristem was damaged. In all species the number of branches from a branching module was independent of module position and plant size (results not shown) so a simple mean number of branches from a module that did branch was assigned to each species. Aeonium urbicum was never observed to branch and was therefore not modelled.

Flowering probability as a function of module number and plant size for the different species is shown in Table 4 . Flowering varied positively with module position in 19 species and in nine species also with plant size. Two species, $A$. davidbramwellii and $A$. lancerottense, had a positive effect of plant size only. The 
TABLE 4. Multiple logistic regression models of flowering probability on module position and plant size. Coefficients of the independent variables are shown in the columns 'module' and 'size' and constants in the column 'constant'. Only significant values are shown $(P<0.05)$. G-statistics and significance of the entire model are given. Degrees of freedom equal the number of significant variables in each model. Abbreviations as in Table 2. The correspondence between model predictions and actual data is shown in the column 'correctly predicted'. The model of the unbranched $A$. urbicum is a simple logistic regression on module position as it never had more than one rosette

\begin{tabular}{|c|c|c|c|c|c|c|}
\hline Species & Constant & $\begin{array}{l}\text { Model } \\
\text { Module }\end{array}$ & Size & $G$ & $\mathcal{N}_{\mathrm{m}}$ & $\begin{array}{l}\text { Correctly } \\
\text { predicted }\end{array}$ \\
\hline \multicolumn{7}{|l|}{ Sect. Petrothamnium } \\
\hline A. goochiae & -2.80 & 0.65 & & $15.24^{* * *}$ & 205 & 0.66 \\
\hline A. lindleyi & -3.56 & 0.78 & 0.003 & $35.60^{* * *}$ & 289 & 0.72 \\
\hline A. sedifolium & -3.16 & 0.77 & 0.001 & $40.80^{* * *}$ & 493 & 0.73 \\
\hline A. viscatum & -3.28 & & & $0.18 \mathrm{~ns}$ & 205 & 0.61 \\
\hline \multicolumn{7}{|l|}{ Sect. Chrysocome } \\
\hline A. smithii & -3.16 & 0.61 & 0.15 & $49.83^{* * *}$ & 355 & 0.67 \\
\hline A. spathulatum & -8.12 & 1.67 & 0.01 & $37.61^{* * *}$ & 184 & 0.87 \\
\hline \multicolumn{7}{|l|}{ Sect. Patinaria } \\
\hline A. canariense & -5.16 & 0.45 & & $8.44^{* *}$ & 79 & 0.78 \\
\hline A. subplanum & -4.57 & 0.71 & & $10.74^{* *}$ & 45 & 0.83 \\
\hline \multicolumn{7}{|l|}{ Sect. Aeonium } \\
\hline A. balsamiferum & -5.59 & 0.44 & & $5.30^{*}$ & 426 & 0.65 \\
\hline A. holochrysum & -6.50 & 0.87 & 0.02 & $188.22^{* * *}$ & 1052 & 0.78 \\
\hline A. manriqueonum & -5.77 & 0.49 & 0.003 & $104.69^{* * *}$ & 1046 & 0.80 \\
\hline A. nubrolineatum & -6.38 & 0.89 & & $222.10^{* * *}$ & 1012 & 0.80 \\
\hline A. undulatum & -6.13 & 0.37 & 0.06 & $53.69^{* * *}$ & 630 & 0.79 \\
\hline A. vestitum & -5.74 & 0.52 & 0.11 & $212.47^{* * *}$ & 1147 & 0.81 \\
\hline \multicolumn{7}{|l|}{ Sect. Leuconium } \\
\hline A. castello-paivae & -8.24 & 1.52 & 0.02 & $41.14^{* * *}$ & 347 & 0.93 \\
\hline A. ciliatum & -6.04 & 0.86 & & $59.53^{* * *}$ & 347 & 0.80 \\
\hline A. davidbramwellii & -3.65 & & 0.30 & $21.67^{* * *}$ & 129 & 0.75 \\
\hline A. deconum & -8.61 & 2.65 & & $24.04^{* * * *}$ & 147 & 0.96 \\
\hline A. haworthii & -6.28 & 0.97 & & $30.09 * * *$ & 361 & 0.86 \\
\hline A. lancenttense & -4.51 & & 0.03 & $3.85^{*}$ & 483 & 0.67 \\
\hline A. percameum & -6.46 & 0.58 & & $59,44^{* * *}$ & 632 & 0.76 \\
\hline A. urbicum & -10.57 & 1.84 & & $27.39^{* * *}$ & 175 & 0.89 \\
\hline
\end{tabular}

combination of large negative constants and small coefficients of module position in these logistic models indicates that shoots were late flowering. That is, many modules are formed along the shoot before it eventually flowers. This is the case in A. canariense, $A$. percameum and all species of section Aeonium, although it is less pronounced in $A$. holochrysum and $A$. rubrolineatum. The 11 species with a significant positive effect of plant size on flowering probability indicated that the earlier the flowering of a shoot, the older the plant. In one species, $A$. viscatum, the two independent variables were poor predictors of flowering, i.e. a flowering event was equally likely at any module and at any plant size.

Branches in most species had a constant angle to their mother shoot regardless of plant size (Table 5). These angles ranged from $61^{\circ}$ in $A$. spathulatum to $90^{\circ}$ in $A$. canariense, $A$. subplanum, $A$. undulatum and $\boldsymbol{A}$. ciliatum. A right angle was characteristic of the latter four few-branched species and therefore not quantified further in the field (therefore not modelled). Seven species had a branching angle that varied with plant size. In general, however, plant size explained only a small proportion of the variation in branching angle as judged by the low $R_{\text {adj }}^{2}$ in the regression models. 
TABLE 5. Simple regression of branching angle on plant size. Significant coefficients and constants are entered in the columns 'size' and 'constant' respectively $(P<0.05) . \mathcal{N}_{\mathrm{m}}$ is the number of modules that form an angle with the mother shoot. The variation due to linear regression is based on $1 \mathrm{df}$; error is based on $\mathcal{N}_{\mathrm{m}}-2 \mathrm{df}$. Abbreviations as in Table 2

\begin{tabular}{|c|c|c|c|c|c|}
\hline \multirow[t]{2}{*}{ Species } & \multicolumn{2}{|c|}{ Model } & \multirow[t]{2}{*}{$\mathbf{R}_{\text {adj }}^{2}$} & \multirow[t]{2}{*}{$\mathcal{N}_{\mathrm{m}}$} & \multirow[t]{2}{*}{$F$} \\
\hline & Constant & Size & & & \\
\hline \multicolumn{6}{|l|}{ Sect. Petrothamnium } \\
\hline A. goochiae & 82.80 & & 0.00 & 64 & 0.52 \\
\hline A. lindlgi & 73.34 & & 0.01 & 61 & $1.46 \mathrm{~ns}$ \\
\hline A. sedifolium & 72.22 & -0.02 & 0.02 & 134 & $4.01^{*}$ \\
\hline A. viscatum & 83.39 & -0.12 & 0.09 & 106 & $10.92^{*}$ \\
\hline \multicolumn{6}{|l|}{ Sect. Chrysocome } \\
\hline A. smithii & 64.09 & & 0.04 & 21 & $1.83 \mathrm{~ns}$ \\
\hline A. spathulatum & 61.23 & & 0.00 & 81 & $0.01 \mathrm{~ns}$ \\
\hline \multicolumn{6}{|l|}{ Sect. Patinaria } \\
\hline A. canariense & 90 & & & & \\
\hline A. subplanum & 90 & & & & \\
\hline \multicolumn{6}{|l|}{ Sect. Aeonium } \\
\hline A. balsamiffrum & 44.11 & 0.74 & 0.18 & 32 & $7.97^{* *}$ \\
\hline A. holochysum & 61.75 & 0.44 & 0.18 & 102 & $23.87^{* * *}$ \\
\hline A. manriqueorum & 84.59 & & 0.001 & 124 & $1.09 \mathrm{~ns}$ \\
\hline A. rubrolineatum & 80.69 & & 0.04 & 19 & $1.67 \mathrm{~ns}$ \\
\hline A. undulatum & 90 & & & & \\
\hline A. vestitum & 92.10 & -0.79 & 0.11 & 41 & 5.99* \\
\hline \multicolumn{6}{|l|}{ Sect. Leuconium } \\
\hline A. castello-paivae & 73.94 & & 0.00 & 174 & $0.27 \mathrm{~ns}$ \\
\hline A. ciliatum & 90 & & & & \\
\hline A. davidbramwellii & 72.97 & & 0.00 & 33 & $0.91 \mathrm{~ns}$ \\
\hline A. deconum & 72.12 & & 0.00 & 84 & $0.22 \mathrm{~ns}$ \\
\hline A. haworthii & 83.75 & & 0.01 & 105 & $2.02 \mathrm{~ns}$ \\
\hline A. lancerottense & 94.55 & -0.27 & 0.05 & 67 & $4.27^{*}$ \\
\hline A. percameum & 70.46 & 0.83 & 0.07 & 76 & $6.54^{*}$ \\
\hline A. urbicum & & & & & \\
\hline
\end{tabular}

The phylogenetic value of growth rules

The five phylogenetic sections of Aeonium represented in this study were significantly separated by the first and second discriminant functions (Fig. 4). Function 1 accounted for $72 \%$ of the variance, function 2 for an additional $16 \%$. Test was based on Wilk's lambda: $\chi^{2}=85.91, \mathrm{df}=44, P<0.001$ for the first function and $\chi^{2}=45.97, \mathrm{df}=30$, $P=0.03$ for the second. Four discriminant functions were produced. All species were correctly classified.

\section{Adaptive radiation and evolution}

Groups of species from the same islands were not separated $\left(\chi^{2}=46.18, \mathrm{df}=44\right.$, $P=0.38$, with $53 \%$ of the variance accounted for by the first function), nor were groups based on habitat preferences $\left(\chi^{2}=21.66, \mathrm{df}=22, P=0.48\right.$, with $69 \%$ of the variance accounted for by the first function). Four and two discriminant functions were produced in each of these two analyses, respectively. 


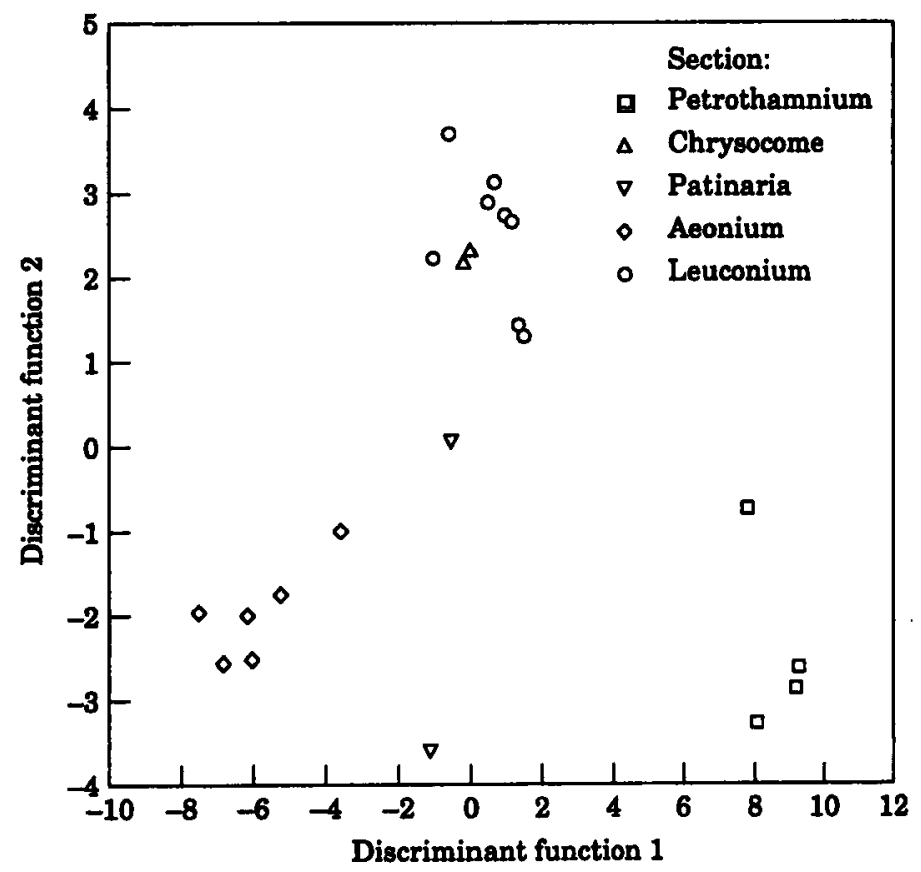

Figure 4. Scores for the first two functions for species grouped by five phylogenetic sections in a discriminant analysis. Sections were significantly separated by the first and second discriminant functions. Function 1 accounted for $72 \%$ of the variance, function 2 for an additional $16 \%$. Test was based on Wilk's lambda: $\chi^{2}=85.91, \mathrm{df}=44, P<0.001$ for the first function and $\chi^{2}=45.97, \mathrm{df}=30$, $P=0.03$ for the second. The division into phylogenetic sections was according to Liu (1989) and based on morphological characters.

\section{DISCUSSION}

\section{Modelling of growth}

The significance level and level of explanatory power of our growth rule models confirm that a dynamic, quantitative approach to plant architecture and modularity is capable of producing general rules. Our simple models seem to be predictors of morphology in many Aeonium species. We regard the models as simple because only four descriptive variables of module morphology and iteration were used, and because position of the module was defined by module number and plant size only.

In some species, these variables explained little or no variation in one or several of the traits. Regression models describing the variation in branching angle were non-significant in all but seven species, while only a few models of flowering and branching turned out to be non-significant. In models of module length, low degrees of explanatory power were mainly seen in the species belonging to the sections Leuconium and Patinaria which consist of creeping plants, subshrubs and the smallest of the shrubs in the genus. When a model had this limited value as descriptor of a trait in a species, other factors or variables than module position and rosette numbers may influence the trait. Another positional variable, such as centrifugal order (cf. Bell, 1991), could be of importance. Also, factors related to the growth history of 
the plant, e.g. preceding branching events, may have explanatory power here. Potential factors of this kind remain to be investigated.

Not all the variation in a trait related to growth form in a population is expected to be predictable in terms of growth rules. Variation in the (micro-)environment of individuals in a population, genotype-environment interactions and phenotypic plasticity of individuals may all influence growth form. Whatever the cause, variability in the phenotype may be of some adaptive and evolutionary significance as it reflects the potential ability of a plant or population to respond to a changing environment (Sachs \& Novoplansky, 1995; Hutchings \& de Kroon, 1994). Our uncontrolled experiments with 22 species, each represented by one population from a single habitat only, have obvious limitations in this respect. Only controlled experiments can disentangle all the causes of variability.

The paucity of data on the duration of the iteration process with respect to the whole plant adds another limitation to the models, as plant maximum size and ageing of the branching species are only partly reflected in the models of flowering probability. This latter variable indicates the termination of a single shoot and is therefore only in the unbranched $A$. urbicum a direct measure of ageing.

\section{The phylogenetic value of growth rules}

Separation of the phylogenetic sections of the genus in the discriminant analysis supports our hypothesis that growth rules do reflect the phylogeny of the genus. Our grouping of species into sections agrees with the established phylogeny based on traditional morphological characters (Liu, 1989). Preliminary investigations indicate that except for one species, $A$. smithii, species group together in clades (Fig. 1) similar to these sections when molecular data are applied (Mes \& Hart, 1996). Mann-Whitney U tests with Liu's (1989) discrete characters as grouping variables, make us reject any possible circularity in the discrimination of the five phylogenetic sections based on growth rule parameters. When species were grouped according to the character states of each of Liu's 23 characters and our 11 growth rule parameters were entered as observations in each group, none of the $11 \times 23$ tests were found significant after sequential Bonferroni corrections for multiple tests were performed (Sokal \& Rohlf, 1995).

Thus, stating the phylogenetic value of growth rules in Aeonium, we suggest that parameters describing and defining growth rules may be of supplementary value in the clarification of taxonomic relationships within plant groups. In many species of Aeonium, module length, for example, appears to vary predictably across the plant. We therefore expect this variability to be genetically determined and a better species characteristic than simple mean value of module length.

\section{Adaptive radiation and evolution}

Various authors have discussed evolution and speciation within the genus Aeonium. From investigations of GAM in the genus, Pilon-Smits et al. (1992) predict that a clustering of species into groups with similar gross growth forms but from different islands is due to parallel evolution of similar growth forms in similar habitats of different islands. The present phylogeny (Liu, 1989; Mes \& Hart, 1996) suggests 
that the gross growth forms have evolved only once in the genus and afterwards dispersed to other islands followed by radiation into different species as a result of isolation (supported by Stevens et al., 1995). This is reflected in species of a clade or section having similar gross growth forms but appearing on different islands.

The discriminant analysis on growth rule parameters did not separate species well, either by island or habitat. If species on similar islands conform to similar growth rules this could either be supportive of the hypothesis of one single event of colonization followed by radiation into several species (Pilon-Smits et al., 1992) or predict selective pressures favouring certain growth rules on certain islands. This latter hypothesis coincides to some extent with that of separation into habitats: certain environmental conditions may favour certain growth rules. This is in agreement with conclusions drawn from the phylogeny of the endemic Argyranthemum of Macaronesia where most inter-island colonization was shown to have occurred between similar climatic regions (Francisco-Ortega, Jansen \& Santos-Guerra, 1996).

Since differences in present day habitats (as classified here) did not separate species well, we predict the growth rule parameters to be related to phylogeny only. This phylogeny does, of course, reflect the summation of all adaptation and dispersal events in the history of the genus. With regard to habitats, the extant species of each section have dispersed and radiated into different sites on the islands without any change in the major characteristics of their dynamic morphology. We do not, however, claim that other morphological traits will not be characteristic or adaptive of certain habitats. The present investigation shows that this is not the case for traits related to growth rules in the genus of Aeonium but might apply to, for example, leaf morphology or anatomical traits. Also, the habitats in which the species have evolved may be different from their present-day states, making past adaptations undetectable in their present day distribution. Climatic or geological changes can, for example, have forced plants to survive under suboptimal conditions.

The ability of our simple model approach to separate phylogenetic sections and to explain some of the variation in growth forms makes us confident that radiation with regard to growth form in this genus is not due to major morphological shifts but to small, gradual changes. Our models offer the species no more than scope for more or less branching, earlier or later flowering and making modules of varying length relative to each other. When considering the phylogenetic tree, some general trends in the evolution of the species can be seen. Petrothamnium is characterized by decreasing module length along the shoot, a low number of branches per branching event, and shoots flowering at an early age. This also applies partly to the species of the sections Chrysocome and Patinaria. Other species seem to differ from these by having an increasing module length and a higher branching frequency along the shoot. The section Leuconium is characteristic by having an even larger, but also very variable, branching frequency. Except for these generalizations, differences among species in the significant regression models are mainly in the magnitude of the coefficients and constants. This emphasises the overall similarity in growth rules within Aeonium and is supportive of the hypothesis of simplicity in evolution of growth forms within the genus. Thus a complexity of growth forms is produced by a simplicity in growth rules.

\section{ACKNOWLEDGEMENTS}

The present work was supported by the Knud Hojgaard Foundation and grants from Mr \& Mrs Svend G. Fiedler to THJ, and The Danish National Science 
Research Council (No. 11-9636-1) toJMO. We thank Pamela Hall, Jes Soe Pedersen and Jakob Nabe-Nielsen for constructive criticism of earlier drafts of this manuscript, Annie Solling for assistance with the labour-intensive measurements and Mr David Clayre for help with the English.

\section{REFERENCES}

Bell AD. 1974. Rhizome organization in relation to vegetative spread in Medeola vinginiana. Joumal of the Amold Arboretum 55: 458-468.

Bell AD. 1984. Dynamic morphology: A contribution to plant population ecology. In: Dirzo R, Sarukhan J, eds. Perspectives on plant population ecology. Sunderland, Mass.: Sinauer, 48-65.

Bell AD. 1991. Plant form. An illustrated guide to flowering plant morphology. Oxford: Oxford University Press.

Bell AD, Tomlinson PB. 1980. Adaptive architecture in rhizomatous plants. Botanical Joumal of the Linnean Society 80: 125-160.

Bramwell D, Bramwell Z. 1990. Flones silvestres de las Islas Canarias. Madrid: Rueda.

Fisher JB. 1986. Branching patterns and angles in trees. In: Givnish TJ, ed. On the economy of plant form and function. Proceedings of the Sixth Maria Cabot Symposium. Cambridge: Cambridge University Press, 493-523.

Francisco-Ortega J, Jansen RK, Santos-Guerra A. 1996. Chloroplast DNA evidence of colonization, adaptive radiation, and hybridization in the evolution of the Macaronesian flora. Proceedings of The National Academy of Science, USA 93: 4085-4090.

Hallé F, Oldeman RAA, Tomlinson PB. 1978. Tropical trees and forests: An architectural analysis. Berlin: Springer.

Harper JL. 1977. Population biology of plants. London: Academic Press.

Hosmer DW, Lemeshow S. 1989. Applied logistic regression. New York: John Wiley \& Sons.

Hutchings MJ, de Kroon H. 1994. Foraging in plants: The role of morphological plasticity in resource acquisition. Advances in Ecological Research 25: 160-238.

Jensen WA. 1962. Botanical histochemistry: Principles and practice. San Fransisco: W.H. Freeman.

Lems K. 1960. Botanical notes on the Canary Islands. 2. The evolution of plant forms in the islands: Aeonium. Ecology 41: 1-17.

Liu H-Y. 1989. Systematics of Aeonium (Crassulaceae). National Museum of Natural Sciences of Taiwan, Special Publication no. 3.

Mes THM, Hart H't. 1996. The evolution of growth forms in the Macaronesian genus Aeonium (Crassulaceae) inferred from chloroplast DNA RFLPs and morphology. Molecular Ecology 5: 351-363.

Mes THM, van Brederode J, Hart H't. 1996: Origin of the woody Macaronesian Sempervivoideae and the phylogenetic position of the East African species of Aeonium. Botanica Acta 109: 477-491.

Norusis J./SPSS Inc. 1994. SPSS advanced statistics ${ }^{\mathrm{TM}}$ 6.1. Chicago: SPSS Inc.

Pilon-Smits EAH, Hart H't, Maas JW, Meesterburrie JAN, Kreuler R, Van Brederode J. 1992. The evolution of Crassulacean acid metabolism in Aeonium inferred from carbon isotope composition and enzyme activities. Oecologia 91: 548-553.

Praeger RL. 1928. The Canarian Sempervivum-flora: its distribution and origin. The Joumal of Botany 66: 218-229.

Sachs T, Novoplansky A. 1995. Tree form: Architectural models do not suffice. Israel Joumal of Plant Sciences 43: 203-212.

Sokal RR, Rohif FJ. 1995. Biometry, 2nd edn. New York: W.H. Freeman and Company.

Stevens JS, Hart H't, Wollenweber E. 1995. The systematic and evolutionary significance of exudate flavonoids in Aeonium. Phytochemisty 39: 805-813.

Sunding P. 1979. Origins of the Macaronesian flora. In: Bramwell D, ed. Plants and islands. London: Academic Press, 13-41.

Sutherland WJ, Stillmann RA. 1988. The foraging tactics of plants. Oikos 52: 239-244.

Voggenreiter V. 1974. Geobotaniche Untersuchungen an der natiullichen Vegetation der Kanareninsel Tenerife (Anhang: Vergleiche mit La Palma und Gran Canaria) als Gnundlage für den Naturshutz. J. Gramer.

White J. 1979. The plant as a metapopulation. Annual Review of Ecology and Systematics 10: 109-145.

Zar JH. 1984. Biostatistical analysis, 2nd edn. New Jersey: Prentice-Hall. 